$12-2009$

\title{
Digital Rights Management, Fair Use, and Privacy: Problems for Copyright Enforcement through Technology
}

\author{
Eric A. Robinson \\ University of St. Augustine for Health Sciences, erobinson@usa.edu \\ Author(s) ORCID Identifier: \\ (D) https://orcid.org/0000-0001-9554-8754
}

Follow this and additional works at: https://soar.usa.edu/other

Part of the Collection Development and Management Commons, and the Intellectual Property Law Commons

\section{Recommended Citation}

Robinson, Eric A., "Digital Rights Management, Fair Use, and Privacy: Problems for Copyright Enforcement through Technology" (2009). Other Topics. 12.

https://soar.usa.edu/other/12 


\title{
Digital Rights Management, Fair Use, and Privacy: Problems for Copyright Enforcement through Technology
}

\author{
Eric A. Robinson \\ San Jose State University \\ https://orcid.org/0000-0001-9554-8754
}

\begin{abstract}
This article discusses the nature of Digital Rights Management (DRM) systems with regard to the problems they pose to traditional exceptions to copyright restrictions. Problems of fair use and the copying of material for preservation are examined in the context of the architecture of digital rights management systems, and the limitations of current DRM systems in accommodating these policies are examined. The monitoring of usage by the licensing modules of these systems is also criticized for its lack of protection of user privacy and the potential chilling of intellectual freedom. Various potential solutions to these are briefly surveyed with a view of improving DRM and preserving traditional library values.
\end{abstract}

\section{Introduction}

The advent of the Internet has enabled the sharing of information on a level unprecedented in human history. Simple and speedy transferral of digital content has created widely available educational opportunities and the possibility for broader dissemination of vast libraries of cultural content like music, art, and film in electronic forms. This incredible ease of dissemination has enabled file sharing and use on vast scales that have strained traditional interpretations of copyright law and spurred larger media firms to invest in digital technologies for controlling use of electronic files. These technologies, referred to as Digital Rights Management (DRM) systems rely upon computer systems to impose restrictions on the use of digital content that adhere to the wishes of the copyright holders, even in situations where individuals have paid for and own the content in question.

Prior to the Internet era, ownership of content artifacts like books or CDs allowed the user the opportunity for relatively free use of the content. Although copyright law would ostensibly restrict unlawful use of material, in reality, economic factors worked more strongly to inhibit copying and distribution of protected content. It was simply time-consuming to photocopy an entire work, only to be left with a copy of vastly inferior quality, e.g., an unbound ream of loose-leaf pages of poor readability (Coyle, 2004a). The time required for duplication and the unsatisfactory product, thus, previously made duplication less desirable than the digital environment does today. Digital content has drastically changed this precarious economic balance, enabling instantaneous duplication and broad dissemination with no loss of quality. Such capability creates incredible potential to adversely affect the marketability and profit-value of created works.

DRM systems were created in an effort to justifiably to constrain illegitimate duplication and 
uses that would violate the legal protections granted to copyright holders, giving the publishers greater control over the use and distribution of their work (Stefik, 1997; Stefik \& Silverman, 1997). The nature of these systems (as they currently stand) remains problematic, however, as they are unable to accommodate the subtleties of copyright law. DRM has regularly been criticized for overreaching the bounds of copyright legislation, enforcing a degree of control in excess of the protections granted under copyright law and hindering the exercise of user rights as granted under the law (Mulligan, 2003; Samuelson, 2003). Logical implementation of the rights of use in DRM software typically falls far short of the subtle consideration needed to evaluate legitimate reproduction or dissemination which traditionally would fall under the exceptions to copyright law known as fair use. Further, many of the schemas implemented by DRM controls rely upon user tracking and retention of information regarding content use that could easily be viewed as violation of the privacy of content users.

This paper will examine briefly the nature of Digital Rights Management Systems (DRMS) and the problems they pose to the conventional exceptions to copyright law. It is argued that the current state of DRMS do not make allowance for the exceptional uses guaranteed under copyright law, and that DRMS need to be further developed to allow for anonymous tracking of user information to ensure intellectual freedom.

\section{DRM Architecture}

DRM systems are intended to control and restrict illegitimate uses of digital media. In defining and controlling access, the DRMS must coordinate a multiplicity of terms and access rights. These access rights may vary with the class of user or the conditions of use. Typically such conditions will be tied to a financial transaction, such as a purchase, a subscription, or some other licensing agreement. All of these parameters must be coordinated to determine the level of access authorization. If access is granted, limited allowances may be made by the system for utilization of the file.

A variety of types of access rights exist which determine how digital content may be used. The most often encountered rights needed in a digital library setting are rendering rights. Rendering refers here to the production of accessible content from an encrypted or controlled file. Rendering can include playback of music, viewing of a video file, and printing or screen-viewing of a text or image file. However, other rights exist that allow transfer of ownership, distribution, or excerption for critical or parodic uses. Each of these possibilities must be explicitly defined and implemented in the DRM.

Erickson (2003) defines a taxonomy of at least four functions which must be served in DRM rendering rights. First and foremost, user actions must be tied to policy-level terms, and any external rendering application must be forced to receive authorization from an evaluation system before allowing content to be rendered. Second, policies must be evaluated by an intermediary system that examines requests and evaluates applicable rules in order to make an authorization determination. Third, governing policies must be in place, defining the rights and conditions of use. Finally these policies must be built into the system and either embedded or linked to the content resource in a machine-readable language. Such systems have been termed "trusted systems" since publishers can assign rights and access conditions and then rely upon the system to enforce those terms (Stefik \& Silverman, 1997).

While a wide range of schemata can be utilized to implement DRM, most are composed of variations 
on the following generic components which implement the taxonomy described by Erickson (2003): a content server with some sort of DRM metadata packaging; a license server which utilizes rights description metadata to to generate access licenses; and a client server with a DRM controller used to determine access from the license and decrypt content for use in various rendering applications as expressed in the rights agreement. The relationship between these elements and their components, as discussed below, is outlined in Figure 1 (Rosenblatt, Trippe, \& Mooney, 2001).

The content server typically houses both the information content repository, containing the actual content files, such as music .mp3 files or text .pdf files, and the DRM packager. The DRM packager relies upon a database of product content metadata to prepare information for digital distribution (Rosenblatt et al., 2001). This component associates metadata for the identification of a content item, as well information for its discovery, but will also contain a complex description of the rights associated with the item. Depending on the level of sophistication of the system, it may also include statistical tracking for usage monitoring. Metadata preparation may be performed in advance and stored with the content or generated as material is downloaded. These rights descriptions are accessed by other components of the DRMS to evaluate users' rendering rights for viewing, printing, transferring or copying content to the conditions of the agreement, and may even restrict the full digital transferral of the data files, instead requiring the user to view the content in an online or streaming format (Rosenblatt et al., 2001).

The license server utilizes the above-mentioned rights descriptions to generate encryption codes or controlled-use licenses for transmission to the client with the content. The DRM license generator houses rights information and the codes

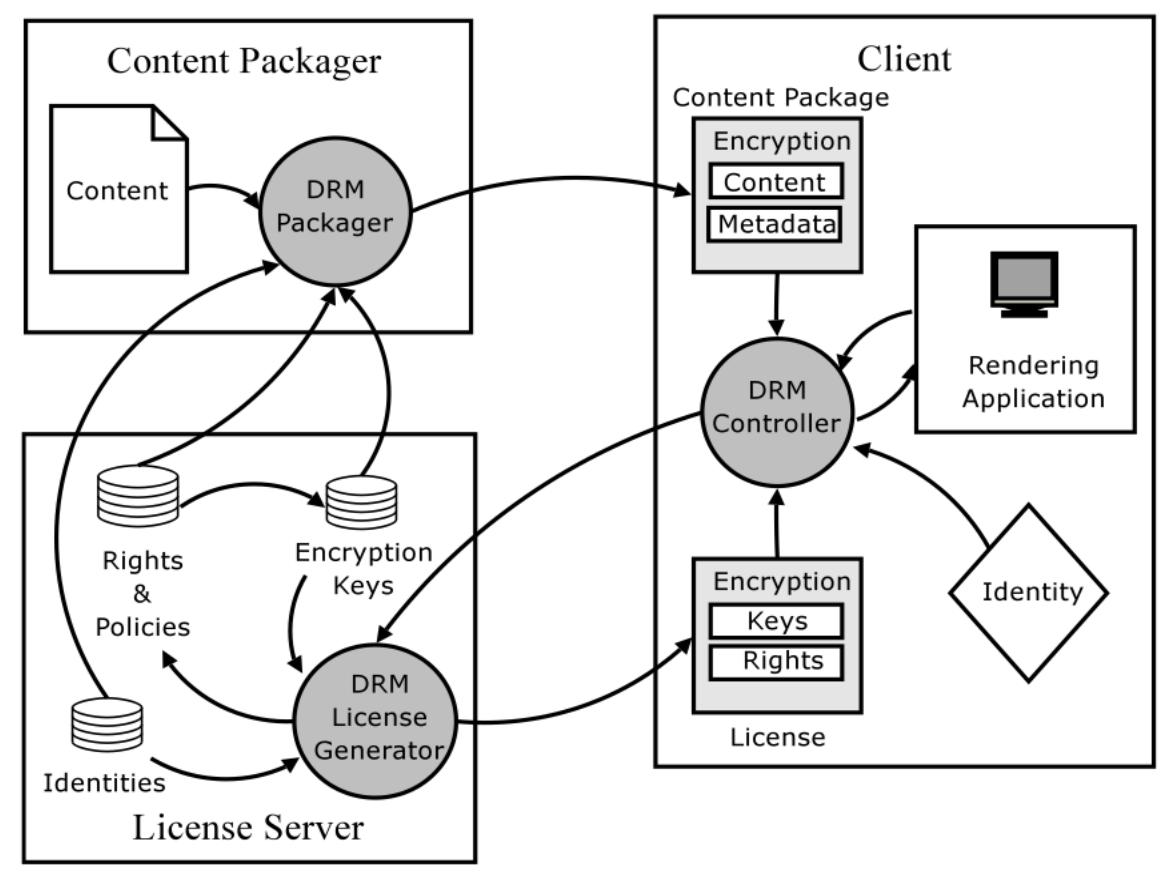

Figure 1: Generic DRM architecture. Source: Rosenblatt et al., 2002. 
for the generation of encryption keys used by the DRM to restrict access beyond the legitimate user. In order to ensure that usage is restricted to licensed limitations, DRMs also require an identity store, which houses information on individual use, e.g. the number of pages of an e-book printed by a user, or the time frame allowed for viewing a document.

The rights defined in these two systems are typically expressed in the form of a Rights Expression Language (REL). RELs provide a machine-readable vocabulary for expressing the relationships among data elements and the policy provisions outlining the conditions of use (D. Mulligan \& A. Burstein, 2002). These are intended to meet three broad goals: the statement of legal copyright, the expression of contractual language in computer-interpretable form, and the implementation of usage controls (Coyle, 2004b). They thus express licensing controls as a digital formatting of permissions. Outlined in the REL will be the parties of a license or contract, statements of classes of access and usage, and necessary financial transaction information (Coyle, 2004b). These basic relationships are outlined in Figure 2.
These relationships attempt to capture the unique conditions for each potential usage permission that might be encountered. They use explicit conditional statements combined with the rights metadata in the content package to comprise directions for action on digital content packages (Erickson, 2003). Thus, as an example, the DRM system might use an REL to express that user A has paid a $\$ 10.00$ fee to access an audio edition of Moby Dick, the rights to which are held by Penguin Press. They will also capture time frame or subscription information expressing that for example, the above user will be able to listen to the audio book as many times as he likes within a three-week period. These systems require very precise language to specify the rights and conditions that is completely unambiguous in order to be expressed in programming code. As we will see in the discussion of copyright exceptions below, this unambiguous expression creates problems for vaguer notions, such as fair use, which are difficult to model in precise language.

The last element of the DRM architecture, the client, is the system employed on the user- side to render the content. It includes several components for controlling access and decrypting content for

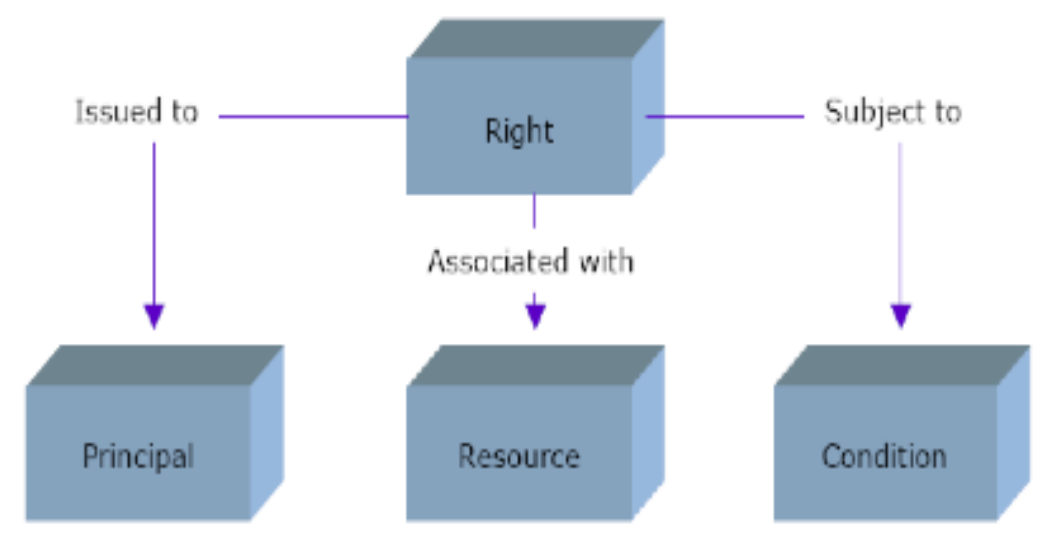

Figure 2: Rights relations in RELs. Source: Coyle (2004b) 
rendering. The main functional component on the client side is the DRM controller. The controller is

the central element of the entire DRM architecture and handles all content authorization requests. This is usually described as a 'virtual machine', a piece of software that runs on top of the computing environment, controlling access to digital content (Arnab \& Hutchison, 2004). It is responsible for accessing content, gathering user identity information, obtaining the license from the license server, authenticating rendering requests, and retrieving decryption keys from the license server. These keys are then used by the client system to decode the file for viewing, printing, listening, etc. Thus, it implements the trusted system function described by Stefik (1997), processing user authorization as defined by the content publisher.

\section{Copyright Law}

In order to understand the significant problems posed DRM, it necessary to consider the motivations of copyright law in Anglo-American history. The legislation has traditionally been focused upon the need to to create an environment that fosters intellectual and cultural advancement. The control of information by DRM, it is often argued, extends far beyond the intentions of copyright law, and works against the principles of societal advancement embodied in the legislation (Lessig, 2004).

The origins of copyright law in the AngloAmerican tradition extends to 1709 and the Queen Anne statute. This statute granted monopoly rights to printers and booksellers, but limited these rights to 28 years, thus assuring economic returns for the creators of intellectual works (Urs, 2004) while still eventually allowing public access to published works. However, the law was also intended by the House of Lords to foster competition among publishers of the period and thus curb centralization of control of information in the hands of a few publishers (Lessig, 2004).

That public progress and societal benefit are at the root of copyright legislation in the US is clearly stated in Article I of the US Constitution in what has come to be known as the Progress Clause: "Congress has the power to promote the progress of science and the useful arts, by securing for limited times to authors and inventors the exclusive right to their respective writings and discoveries" (Bailey, 2006). Lessig (2004) argues that this statement of the power of Congress is granted in order to promote progress and that the primary motivation of copyright is not one of creator reward, but rather the Progress Clause encapsulates the need to stimulate the creation of intellectual works. While the extent of the forefathers' interest in author compensation can be debated, copyright law is, at a minimum, viewed by legal scholars as facilitating a balance-rights of compensation for the authors for their creation balanced with the rights of the public to utilize that information freely (Ferullo, 2004).

Actual legislation of rights to copy works came with the US Copyright Act of 1790, which granted creators limited protections to control reproduction, distribution, and performance of their works, again with a limit of extension totaling 28 years. Such limitations set upon copyright registration showed that the authors of this legislation viewed eventual entry into the public domain as an important process for social progress. However, the laws have been amended several times, creating a rather complex system of determining whether a work is in the public domain. The length of protection of works has been extended eleven times in the last forty years, and the average term has tripled to 95 years (Lessig, 2004). 
These laws, as formulated over centuries, grant to the copyright holder several very specific, but limited rights to control the use of created content. These include, most importantly the rights of reproduction, modification, and distribution. Holder rights also include the rights for public performance and public display. These rights also allow the holder to transfer rights the abovementioned rights to a third party, such a publisher, in order to disseminate the work (Urs, 2004). With regard to DRM, reproduction and distribution rights are those which are most critical as will be seen below.

\section{Exceptional Uses and DRM}

As has been mentioned, the rights of the creator are not all-encompassing. There are express exceptions to these constraints that have been deemed necessary for the good and advancement of society (Cohen, 2003a; Lessig, 2004, Bailey, 2006). These reflect some of the vital ways in which information is used, and these protections have served to maintain intellectual progress without undue hindrance by the commercial interest of copyright holders. These exceptions include rights to sell or transfer ownership, rights to duplicate protected content under certain conditions, the right to duplicate material for preservation purposes, and the right to reproduce content under the doctrine known as 'fair use'.

First sale doctrine refers to the disposition of ownership that typically accompanies the purchase or a work. This doctrine grants users the right dispose of their legally obtained copy of a work as they wish, for example, by selling or transferring ownership. This is one of the founding legal principles of lending libraries, in that they are given legal allowance to loan books to their users without being seen as infringing upon the distribution monopoly granted by copyright, since the are not duplicating, but only temporarily transferring possession of the protected content (Anderson, 2002).

Under DRM, express permissions outlining acceptable transferal of possession or ownership are necessary for lending of digital content. Under traditional copyright law, such transferal is not subject to control. Thus, any technological hindrance or limitation on transfer or lending presses traditional interpretations of copyright law into new territory. Under digital licensing agreements, libraries may be forced to agree to limitations on transferal of content far beyond what those of traditional physical media to the extent that their ability to lend works is compromised.

Further, the nature of digital transfer raises a new issue in the nature of 'lending' of digital material. In the digital age, every transferal of content over the Internet, even transferal for temporary use, creates a copy which is transmitted. That is, the digital transfer, as a copy, potentially places each legitimate use under the control of the copyright holder. (Lessig, 2004) This forces the traditional exceptions to copyright law to bear a burden not previously encountered in lending prior to the digital era.

Another exception granted for archiving purposes protects the act of preservation by allowing the production of copies of published or unpublished works for preservation or to replace legitimately acquired works if they are damaged or lost. Under DRM, digital content is very restricted in the ways that it can be copied, frustrating the attempts of libraries to preserve content that they legally own or or to backup digital content in the way that a traditional work might be copied for the purposes of preservation. Without recognition within the REL for archiving and preservation needs, legitimate duplication is simply not permitted. 
Fair use is the most controversial of the exceptions made to copyright restrictions, but also one of the most important for education and libraries. Under the interpretation of fair use, users can make single copies for personal or educational use of limited portions of a copyrighted work. The concept of fair use is enshrined in section 107 of the Copyright Act of 1976 and reflects many years of court decisions recognizing the legitimacy of these exceptions (American Library Association, 2009). Fair use is the most contentious of the exceptions since it is, by intention, so vaguely defined in the Copyright Act. Schulman writes that "differentiating between fair and unlawful use is often one of the most difficult problems in the law of copyright" (1967, p. 832), noting that the facts must be weighed on a case by case basis.

Indeed no simple a priori test for fair use has been established; rather several factors are often relied upon and weighed in the judicial balance to determine if a use should be deemed legitimate (Coyle, 2004a). These include: the nature or purpose of the use; the nature of the original work; the portion of the protected work used; and the impact of the use upon the market (Felten, 2003, Crews 2006).

Each of these exceptions creates a problem that ought to be accommodated by any DRM system. However, the imprecise definitions of these uses are difficult if not impossible to implement. Fair use is viewed as one of the most critical problems for the architecture of DRM systems, since it must be typically judged on a case by case basis and cannot be subjected the strict rule-based logic of computer software. Since it is so vaguely defined, it is nearly impossible to implement representation of all possible expressions of fair use within the REL in advance (Tyrvainen, 2005). As Edward Felten has expressed, "an approach that makes errors in only one direction simply makes too many errors, so we must accept that any practical system is both too permissive and too restrictive" (2003, p. 58). That is, given the need to express these restrictions in machine-interpretable ways, any system that could restrict all uses unacceptable to the copyright holder will necessarily inhibit uses deemed legitimate by fair use principles. As we will see, however, there may be hope for the creation of rights descriptions which might incorporate fair use and other elements in the coding of Rights Expression Languages.

Over the last several years, international treaties sponsored by the World Intellectual Property Association have promoted treaties requiring national legislation for greater copyright protection of works in digital format (Szcezepanksa , 2004). These have led to very controversial provisions which can be seen as paradoxical when viewed in light of the exceptions to copyright discussed above. The Digital Millennium Copyright Act of 1998, an amendment to Title 17 of the United States Code, certainly created paradoxical provisions. The so-called anticircumvention provision of the DMCA prohibited the circumvention or promotion of technologies for the circumvention of DRM protections (Lipton, 2005).

This becomes seriously problematic when the DRM measures assert control beyond the protections of copyright law. Under these conditions the law forbids someone from decrypting or tampering with anti-viewing or anticopying measures, even if those measures prevent the user from engaging in legitimate uses as defined by the Copyright Act. That is, by engaging in acts that allow them to exercise legally protected rights disallowed by a DRM system, users would be committing a crime (Bailey, 2006). This makes it extremely difficult for users to engage in fair use of a vast amount of protected content. 


\section{Privacy}

The implementation of digital control on the use of content also has significant implications for user privacy. Stakeholders have increasingly begun to turn to surveillance to enforce copyright protections in real-time. At a minimum, DRM technologies place limitations on what individuals can do in the privacy of their own homes and regularly go further, monitoring the actions of users in a variety of contexts. Culturally, there have been expectations of limits on the contraint of behavior in this way. Legally, privacy has been defined in terms of other mechanisms such as tort laws regarding defamation or breach of confidence (Ganley, 2002). It is questionable whether any circumstance should allow external elements to determine acceptable private behavior with regard to information use (Cohen, 2003b). However, courts have not yet considered whether privacy protections under tort law extend to the monitoring conditions of DRM systems.

More worrisome is the possibility of DRM technology reporting back to the provider on user activities. Such monitoring is commonplace in online shopping to collect data on user preferences for targeted marketing purposes. This data collection can also be employed in an information environment and used to discover user preferences for digital content. In most DRM situations however, monitoring is of content usage. That is, an identity store on the licensing server might record information on the number of viewings a particular item has been given, or the number of pages printed, or to whom a particular copy is registered.

Although this monitoring is automated, this does not obviate the problem, for anytime that such information is collected it is subject to unauthorized disclosure. Even if data is recorded only to be associated with the user in ambiguous ways, it is deemed by experts still to be linkable to the individual with little effort (Korba \& Kenny, 2003). The possibility of such disclosures have a strong potential to chill information seeking behavior. That is, when individuals expect their behavior to be subject to observation, they will behave differently, especially regarding more controversial subjects. Such a chilling of behavior is not conducive to democratic principles and efforts to ensure privacy of information consumption has come to rank among the principles of librarianship and the promotion of a well-informed democratic populace (Office for Intellectual Freedom, 2009).

\section{Solutions}

The problems of legitimate use and user privacy have long been debated in the literature, particularly since the enactment of DMCA in 1998, and a number of solutions have been proposed and developed. These range from the creation of an administration agency to examine claims of fair use access (Lipton, 2005), to developments and advancements in the coding process which are able to more accurately capture the subtleties of fair use in the DRM environment (Arnab \& Hutchison, 2005; Ganley, 2002; Korba \& Kenny, 2003).

One possibility for adjusting the range of control involves user definition or user involvement in the definition of rights descriptions. One of the major criticisms of DRM is that users do not have an opportunity to negotiate the terms of the license. These licenses are either 'click-through' licenses to be read and agreed to, or 'shrink-wrap' licenses, which are a non-negotiable elements of a packaged software products. In neither case is the user able to redefine or mediate the terms of the agreement in any way.

Ganley (2002) and Mulligan \& Burstein 
(2002)make a case for the use of XML to expand on rights expression languages such as the Extensible Rights Markup language (XrML) to allow user participation in defining rights. Since XML allows the customized definition of tags for describing the nature of an information element, Ganley argues that users could be allowed to define tags which capture agreements to which they are willing to submit. Users could thus be involved in defining the data of the REL, rather than being subject to the imposition of a single licensing framework. This would allow the user greater control in defining the licensing agreement.

Arnab and Hutchinson (2005) propose a similar mechanism in the form of a 'bi-directional REL', that allows users to express their needs. Bidirectional languages would allow the users to better communicate their content requests and their intent of use in machine-evaluable terms. The DRMS could then examine the user request in the form of a REL, and either approve their license request or provide them with similar options. This type of REL has been implemented in the Open Digital Rights Language (ODRL), and models of negotiable rights languages continue to be developed upon.

Tyravainen (2005) offers yet another variation on this in the form of a license template, which the user employs to create a license request to which the system responds with a digital license. He proposes a list of potential licenses and associated template requests. These would essentially allow users to apply for exceptional uses, such the provision of a personal backup copy.

Another solution to the fair use problems that has been proposed involves the assignment of rolebased credentials (Arnab \& Hutchison, 2005). Under this model users would be granted exceptional licenses according to the credentials associated with their account. For example, a journalist might be given greater leeway for excerption for citation, given his professional credentials. By writing a new rule-based condition into the REL, the DRM could allow certain rights given the presence of the credential. Of course, this would require the maintenance of additional information in some sort of identity store, working counter to the need for privacy arrangements.

The primary solution to the question of privacy of content access concerns the degree of information tracking by the licensing module. Such tracking is deemed as necessary to commercial viability and the public seems to endorse an element of such data tracking in the form of product recommendations (Ganley, 2002). Given the apparent demand for usage monitoring, a minimum provision for privacy would necessitate the separation of user identifying information from any product tracking information. Such separation is indeed part of Tyrvainen's (2005) proposal, but more is needed to help ensure that ambiguous data cannot be assembled for individual identification.

Cohen (2003b) argues for greater legal involvement in this process, calling on representatives to create specific legislation which addresses these needs. Specification of a privacy 'bill of rights' for users of information products would force DRM developments that better respect information privacy.

\section{Conclusion}

Given the tighter controls being placed on digital content and the broadening protections of the rights of copyright holders, it is becoming increasingly difficult to access a broader range of content for personal uses that have traditionally stood outside the protection of copyright law. The rapid increase in size of electronic collections 
makes it more likely that the majority of library content will become subject to DRM enforcement.

The traditions of copyright law have been to recognize that there is value in public access to information, and that some uses of information are exceptional and ought not be subject to the usual restrictions on copyrighted material. Long held values of intellectual freedom dictate privacy of information access. In the physical library these values were more easily protected. If the nature of information access is not to drastically to change in the Internet era, these traditions must also be accommodated in DRM. As information professionals aware of the social and ethical implications of these traditions, we must work to create alternatives to the current DRMS, which do not provide for important accommodations of fair use and privacy. Progress is being made in technological developments of rights expression languages like ODRL, and while it may be difficult to implement the every aspect of the subtleties of fair use and privacy restrictions it is certainly possible to make improvements. Wider awareness of these issues can spur further research and create a demand for improved legislation and modified access systems which will better support these provisions. 


\section{References}

American Library Association. (2009). What is fair use? American Library Association. Retrieved December 5, 2009, from

http://www.ala.org/Template.cfm?Section=cop yrightarticle\& Template $=/$ ContentManagement /ContentDisplay.cfm\&ContentID $=26700$

Anderson, B. (2002). First sale, digital copyright, and libraries. Behavioral \& Social Sciences Librarian, 21(1), 73-76.

Arnab, A., \& Hutchison, A. (2004). Digital rights management-An overview of current challenges and solutions. In Proceedings of Information Security South Africa (ISSA) Conference 2004.

Arnab, A., \& Hutchison, A. (2005). Fairer usage contracts for DRM. In Proceedings of the 5th ACM workshop on Digital rights management.

Bailey, C. W. (2006). Strong copyright + DRM + weak net neutrality $=$ digital dystopia.

Information Technology and Libraries, 25(3), 116-127.

Cohen, J. E. (2003a). DRM and Privacy. Communications of the ACM, 46(4), 47-49.

Cohen, J. E. (2003b). DRM and Privacy. Berkeley Technology Law Journal, 18, 575-617.

Coyle, K. (2004a). The technology of copyright: digital rights management. Retrieved November 11, 2009, from http://www.kcoyle.net/drm basics.pdf

Coyle, K. (2004b). Rights Expression Languages: a Report for the Library of Congress. Library of Congress. Retrieved November 10, 2009, from www.loc.gov/standards/relreport.pdf.
Crews, K. (2006). Copyright Law for Lbrarians and Educators: Creative Strategies and Practical Solutions (2nd ed.). Chicago, IL: ALA Editions.

Erickson, J. S. (2003). Fair use, DRM, and trusted computing. Communications of the ACM, 45(4), 34-39.

Felten, E. W. (2003). A skeptical view of DRM and fair use. Communications of the ACM, 46(4), 56-59.

Ferullo, D. L. (2004). Major copyright issues in academic libraries: Legal implications of a digital environment. Journal of Library Administration, 40(1/2), 23-40.

Ganley, P. (2002). Access to the individual: Digital rights management systems and the intersection of informational and decisional privacy interests. International Journal of Law and Information Technology, 10(3), 241.

Korba, L., \& Kenny, S. (2003). Towards Meeting the Privacy Challenge: Adapting DRM. In Digital Rights Management, Lecture notes in computer science (Vol. 2696, pp. 118-136). Berlin: Springer.

Lessig, L. (2004). Free culture: How big media uses technology and the law to lock down culture and control creativity. New York: Penguin.

Lessig, L. (2006). Code: And Other Laws of Cyberspace, Version 2.0. New York: Basic Books.

Lipton, J. (2005). Facilitating fair use in the digital age. Information \& Communications Technology Law, 14(3), 279-298. 
May, C. (2007). Digital Rights Management: The Problem of Expanding Ownership Rights. Oxford, England: Neal-Schuman Publishers.

Mulligan, D., \& A. Burstein. (2002). Implementing Copyright Limitations in Rights Expression Languages. In Proceedings of the 2002 ACM workshop on Digital Rights Management (2002), ACM (pp. 137-154).

Mulligan, D. K. (2003). Digital rights management and fair use by design. Com, 46(4), 31-33.

Office for Intellectual Freedom. (2009). Intellectual Freedom Manual (7th ed.). ALA Editions.

Rosenblatt, W., Trippe, W., \& Mooney, S. (2001). Digital Rights Management: Business and Technology (1st ed.). New York: Wiley.

Samuelson, P. (2003). DRM \{and, or, vs. \} the law. Communications of the ACM, 46(4), 41-45.

Schulman, J. (1967). Fair Use and the Revision of the Copyright Act. Iowa Law Review, 53, 832.

Stefik, M. (1997). Shifting the possible: How trusted systems and digital property rights challenge us to rethink digital publishing. Berkeley Tech. LJ, 12, 137.

Stefik, M., \& Silverman, A. (1997). The Bit and the Pendulum: Balancing the Interests of Stake-Holders in Digital Publishing. American Programmer, 10, 18-35.

Szcezepanksa , B. (2004). Digital is not different-copyright in the digital age. In IATUL Annual Conference Proceedings. International Association of Scientific and Technological University Libraries.

Tyrvainen, P. (2005). Concepts and a Design for
Fair Use and Privacy in DRM. D-Lib Magazine, 11(2). Retrieved November 15, 2009, from

http://webdoc.sub.gwdg.de/edoc/aw/dlib/dlib/february05/tyrvainen/02tyrvainen.html

Urs, S. R. (2004). Copyright, academic research and libraries: balancing the rights of stakeholders in the digital age. Program: electronic library and information systems, 38(3), 201-207. 